\title{
TRADUÇÃO OS TRÊS NÍVEIS DO JUÍZO MÉDICO Paul Ricoeur
}

Phainomenon, n. ${ }^{\circ}$ 15, Lisboa, pp. 179-182.

DOI: 10.2478/phainomenon-2008-0010

(C) 2008 Henriques. This is an open access article licensed under the Creative Commons AttributionNonCommercial-NoDerivs License (http://creativecommons.org/licenses/by-nc-nd/3.0/). 


\section{APRESENTAÇÃO}

A escolha de traduzir o presente texto ficou a dever-se a uma série de razões, umas extrínsecas outras intrínsecas ao pensamento de Paul Ricœur.

Das razões extrínsecas a assinalar, pode destacar-se não apenas o interesse do tema e a sua actualidade, mas igualmente a pertinência da reflexão nele desenvolvida e as questões diversificadas que levanta. Esse conjunto de motivos transforma o texto num óptimo recurso de trabalho num quadro de várias finalidades.

Todavia, foram essencialmente as razões intrínsecas ao próprio pensar Ricœuriano que determinaram a escolha do texto. Essas razões são, nomeadamente, por um lado, o facto de o texto revelar a faceta de compromisso da prática filosófica de Ricœur, por outro lado, a sua composição argumentativa, em ritmo triádico, ser o modo mais específico de constituição da textualidade Ricœuriana e, por fim, essa argumentação evocar três temáticas fulcrais da sua filosofia: o conflito, a promessa e o paradoxo.

\section{§1. Paul Ricœur e o compromisso da filosofia e do filosofar}

François Dosse, na sua biografia sobre Ricœur, Paul Ricœur-Les sens d'une vie, diz, a propósito da dimensão comprometida do pensamento daquele autor:

Telle est la posture philosophique de Paul Ricœur qui, depuis les années trente, conçoit sa réflexion comme une longue forme d'engagement dans la Cité. Prende connaissance de son itinéraire atteste cette capacité d'intervention constante dans les grands enjeux qui traversent la société contemporaine. Il montre à quel point la voie philosophique, tout en restant modeste, est majeure et nécessite de longs détours, une véritable ascèse intellectuelle. À plus de quatre-vingts ans, Ricœur fait la démonstration d'une éternelle jeunesse. Sa présence constante dans ce siècle ne se sera jamais démentie. Si être est " être en chemin », Ricœur, maître à penser plus que maître penseur de générations sucessives, est bien au coeur du XX $\mathrm{X}^{\mathrm{e}}$ siècle, au cœur de la Cité. ${ }^{1}$

${ }^{1}$ François Dosse, Paul Ricœur - Les sens d'une vie, Paris, Esprit, 200, p. 7. Paul Ricœur expressa este seu compromisso com a Cidade no belo texto da Introdução a Histoire et Vérité: "A palavra é o meu reino e não tenho vergonha disso; [...]. Como universitário, creio na 
Na verdade, houve desde o início do labor filosófico de Paul Ricœur uma preocupação cerrada com a dinâmica política e cultural sua contemporânea, sobre a qual sempre interveio reflexivamente, fiel, aliás, ao princípio hegeliano de que a filosofia deve ser o pensamento do seu tempo.

Nessa medida, quer como cidadão, quer como filósofo, Paul Ricœur é a expressão de uma vida e de um pensar comprometidos com os temas e os problemas decorrentes não só do desenvolvimento histórico-cultural como também os que a prática filosófica do século XX fez emergir. Para citar apenas um exemplo, basta referir o seu texto O paradoxo político - texto incontornável no âmbito da filosofia política - cuja motivação primeira é, como ele próprio diz, transformar a surpresa e o abalo ocasionados pelo "Acontecimento de Budapeste" em reflexão sobre as estruturas do Poder. ${ }^{2}$

A faceta comprometida do filósofo foi-lhe publicamente reconhecida muitas vezes, estando uma delas exactamente ligada com o assunto analisado no presente texto - o escândalo francês do sangue contaminado que envolveu Geogirna Dufois, antiga Ministra des Affaires sociales et de la Solidarité national, no contexto do qual, em 1999, Paul Ricœur, enquanto filósofo, foi chamado a depor no sentido de esclarecer a pertinência ética da expressão "responsable mais pas coupable" que analisou como especialista. ${ }^{3}$

Todavia, o compromisso do seu pensar tem uma raiz ontológica - dizer sim à existência, assumindo-se como ser no mundo -, ao mesmo tempo que põe de relevo uma dimensão ética insuperável de todo o discurso.

\section{§2 Paul Ricœur entre o trágico e a promessa}

\section{Entre l'hermeneutique et le savoir absolu il faut choisir!}

Paul Ricœur pronuncia muitas vezes esta afirmação para marcar o quadro conceptual da racionalidade hermenêutica, claramente inscrita no âmbito de uma racionalidade limitada. Esse seu gesto define a filosofia hermenêutica no campo da finitude como irrecusável e leva-o a tornar-se exímio num tipo de análise pautado pela tríade argumentativa, no quadro das mediações imperfeitas, ou seja, sempre aquém de uma síntese superadora.

É no âmbito das mediações imperfeitas que ganham sentido, em simultâneo, três temas maiores da filosofia Ricœuriana: o conflito, o paradoxo e a

eficácia da palavra que ensina; como professor de história da filosofia, creio no poder esclarecedor, mesmo para uma política, de uma palavra consagrada a elaborar a nossa memória filosófica; como membro da equipa Esprit, creio na eficácia da palavra que retoma, reflexivamente, os temas geradores de uma civilização em marcha; como ouvinte da pregação cristã, creio que a

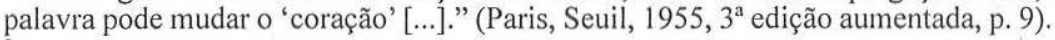

2 Cf., Paul Ricœur; Histoire et Vérité, op. cit., pp. 260-285.

${ }^{3}$ Cf., Paul Ricœur, Le Juste 2, Paris, Esprit, 2001, pp. 289 ss. 
promessa. Por isso, Ricœur é um pensador trágico e do trágico. É no interior do paradigma trágico que a sua abordagem do Mal se compreende. Disse-o em La Symbolique du mal, nos anos 1960, repetiu-o nos anos 1980 em Le Mal. Un défi à la philosophie et à la Théologie, embora nesta última obra - peça fundamental para abordagem do tema do mal no pensamento contemporâneo - Ricœur, abrindo uma alternativa à abordagem teórica do Mal, apresente a via da acção e da espiritualidade como uma resposta possibilitadora da coabitação humana com o mal num mundo de uma racionalidade limitada.

A abordagem teórica do mal ou se deixa levar pela teodiceia, ao modo de Leibniz e Hegel e retira à questão do mal o seu lado escandaloso e assim passa ao lado da vivência humana do mal, ou, então, tem de reconhecer que a abordagem teórica do mal conduz inevitavelmente ao paradoxo da existência e tem de procurar uma via outra para poder "explicar mais para compreender melhor"; ou seja, tem de se abrir a uma racionalidade que saiba aliar a finitude e o plano conceptual.

O paradoxo é o limite inevitável de uma racionalidade limitada, mas que, apesar disso, não desiste de "explicar mais para compreender melhor"; isto é, não desiste de articular os limites da razão e a força clarificadora do conceito. Nesse sentido, embora saiba que a razão não pode oferecer uma visão discursiva unificada e reconciliada sobre o real, não pactua com qualquer forma de intuicionismo ou irracionalismo. Sendo, a um tempo, uma razão finita e discursiva, a razão Ricœuriana é, digamos, uma razão voluntariosa que não desiste de pronunciar a palavra racional possível.

O paradoxo é, no plano da racionalidade, a resposta à Aufhebung hegeliana, representando a afirmação de que a razão discursiva não se resolve em reconciliação, mas sim em crise. Esta limitação conceptual própria de uma razão finita vai obrigar todo o discurso a uma inscrição ética: perante a situação paradoxal em que a argumentação racional desemboca, é necessário comprometer-se numa escolha para poder prosseguir-se uma análise teórica ou uma acção. Isto é, se o paradoxo é a última fronteira explicativa, então, cada sujeito é obrigado e enfrentar a dimensão dilemática do real e a orientar-se nele através de uma decisão.

O presente texto ilustra bastamente a crise constitutiva da análise racional do pacto de cuidados médico, apontando uma série sucessiva de situações assimétricas e de fragilidades da prática médica e que se consubstanciam no paradoxo essencial configurado pela antinomia: dimensão privada e singular do sofrimento, base da doença, e o aspecto público da saúde.

Este é o princípio paradoxal que regula toda a prática médica e qualquer análise compreensiva dela. É ele também que condiciona as escolhas relacionadas com as políticas de saúde que legislam sobre o tipo de contrato de cuidados de saúde que deve ligar pacientes e médicos, ora centrando-se na livre escolha por parte dos pacientes e afirmando o direito individual como ilimitado, ora reforçando o princípio da saúde como um bem público e que, como diz Ricœur, pode querer acentuar que a dignidade da "vida humana pode 
também ser entendida no sentido da maior extensão das populações, mesmo do género humano na sua totalidade", impondo, necessariamente, limites aos direitos individuais em nome de regras de solidariedade.

Nessa medida, o que o texto evidencia é a dimensão complexa e nunca neutra de qualquer tomada de posição no campo da bioética, tomada em sentido lato e não apenas como o patamar vigilante das tecnociências.

A racionalidade paradoxal articula-se directamente com duas outras dimensões epistemológicas próprias do pensar Ricœuriano: a do conflito entre interpretações, que define a natureza cindida do campo hermenêutico e a da promessa que aponta para uma ontologia apenas concebida no âmbito da metáfora da Terra Prometida.

O texto escolhido para traduzir vive de, ao mesmo tempo que ilustra, qualquer das dimensões citadas.

Desde logo, o conflito é nele uma categoria recorrente.

Qualquer dos níveis do juízo médico - prudencial, deontológico e reflexivo - é estruturado pelo conflito; começa pelo conflito decorrente da inscrição estatutária de cada interveniente bem como da interpretação que cada interveniente faz dessa mesma inscrição, continua com o conflito assente na oposição dos interesses da pessoa com os da sociedade e termina com o conflito entre as filosofias que sustentam os diferentes níveis de análise. Daí que as palavras-chave da análise sejam: pacto, contrato e não-dito. As duas primeiras apresentam-se como as formas possíveis de dirimir humanamente um conflito de situação ou de interesses; a última revela o elemento residual insuperável de qualquer análise racional finita. Não há, portanto, processo de se aceder a situações transparentes ou puras. A racionalidade que assume o paradoxo como resposta à possibilidade de uma Aufhebung ficará sempre acantonada a um fundo irrecusável de não-saber e de obscuridade.

É neste contexto que se abre o campo da Promessa, quer no plano do agir, quer no plano do ser. Ao nívél do agir, através da compromisso perante a palavra dada. Ao nível do ser, pela esperança de que a unidade advenha em sentido último.

Fernanda Henriques 